\title{
Investigation of geochemical characteristics and its geological significance of the Triassic oilfield brine in the Sichuan Basin
}

\author{
LI QIANWEN ${ }^{123}$ \\ ${ }^{1}$ Sinopec Petroleum Exploration and Production Research \\ Institute, Beijing, China, 100083
}

Oilfield brine refers to the formation water associated with oil and gas in the reservoir, studying the properties and geochemical characteristics of oilfield brine is of great significance for analyzing the formation, migration and accumulation of oil and gas reservoirs. The Triassic formation in the Sichuan Basin is not only rich in petroleum, but also has oilfield brine with wide distribution, high quality and great exploitation value. Researches show that the brine in Sichuan Basin is distributed in 9 major formations and 21 regional areas, which are mainly enriched in Xuanhan and Wolonghe in the Northeast Sichuan, Pingluoba structures in the West Sichuan, Ziliujing and dengjingguan in the Southwest Sichuan, and vertically developed in the Feixianguan Formation ( $\left.\mathrm{T}_{1} \mathrm{f}\right)$, Jialingjiang Formation $\left(\mathrm{T}_{1-2 \mathrm{j}}\right)$ and Leikoupo Formation $\left(T_{2} 1\right)$. The TDS of the oilfield brine can amount to $24.84-383.95 \mathrm{~g} / 1$ with an average of $174.3 \mathrm{~g} / \mathrm{l}$, reaching the level of concentrated brine. Some elements in brine such as $\mathrm{K}, \mathrm{Na}$, $\mathrm{Br}, \mathrm{Li}, \mathrm{Sr}$ and $\mathrm{B}$ can reach industrial mining grade. Except the Xujiahe Formation $\left(\mathrm{T}_{3} \mathrm{xj}\right)$ in the Southwest develops yellow brine, the other areas and formations are all developed with black brine. By analyzing chemical characteristic coefficients including TDS, $\mathrm{r}_{\mathrm{Na}} / \mathrm{r}_{\mathrm{Cl}}, \mathrm{r}_{\mathrm{Na}} / \mathrm{r}_{\mathrm{K}}, \mathrm{r}_{\mathrm{Mg}} / \mathrm{r}_{\mathrm{Cl}}, \mathrm{Br} / \mathrm{Cl}, \mathrm{Ca} / \mathrm{Sr}, \mathrm{SO}_{4} / \mathrm{Cl}$, it can be concluded that the oilfield brine in the east of Sichuan Basin is mainly the composite cause of sedimentary metamorphic brine and solid potassium beneficial solution filtration, however, the oilfield brine in the west basin consists of marine brine from middle Triassic, nonmarine brine from upper Triassic and the dissolution of marine evaporates in burial strata of middle Triassic. 